\title{
Oxytocin Attenuates
} Methamphetamine-Induced Apoptosis via Oxytocin Receptor in
Rat Hippocampal Neurons

\author{
Chunli Li*, Haipeng Wang, Min Wang, Chunyun Chen, Fei Bai, Mengqi Ban and Chunfu Wu* \\ Department of Pharmacology, Shenyang Pharmaceutical University, Shenyang, China
}

\section{OPEN ACCESS}

Edited by:

Hanting Zhang,

Qingdao University, China

Reviewed by:

David Pubill,

University of Barcelona, Spain

Zhuang-Li Hu,

Huazhong University of Science and

Technology, China

*Correspondence:

Chunli Li

lichunli_2014@126.com

Chunfu Wu

Chunfuw@gmail.com

Specialty section: This article was submitted to

Neuropharmacology,

a section of the journal

Frontiers in Pharmacology

Received: 09 December 2020

Accepted: 29 July 2021

Published: 12 August 2021

Citation:

Li C, Wang H, Wang M, Chen C, Bai F, Ban M and Wu C (2021) Oxytocin Attenuates MethamphetamineInduced Apoptosis via Oxytocin

Receptor in Rat

Hippocampal Neurons.

Front. Pharmacol. 12:639571. doi: 10.3389/fphar.2021.639571
Methamphetamine (METH) is a highly neurotoxic psychoactive substance that can directly damage the central nervous system through prolonged use. Oxytocin (OT) has attracted much attention because of its neuroprotective effect. The purpose of this study was to investigate whether OT is neuroprotective against METH-induced damage in rat hippocampal neurons. Our results revealed that pre-incubation with OT significantly prevented the damage of METH to hippocampal neurons, including the decrease of mitochondrial membrane potential and the increase of ROS (reactive oxygen species). OT pre-incubation attenuated the up-regulation of Cleaved-Caspase-3 expression and the down-regulation of Bcl-2/Bax expression induced by METH. Pre-incubation with OT prevented the decrease in oxytocin receptor density and P-CREB (phosphorylation of cAMP-response element binding) expression induced by METH in rat hippocampal neurons. Moreover, Pre-incubation of atosiban (ATO) significantly prevented these changes. In conclusion, our study proved that pre-administration of OT could significantly attenuate hippocampal neuron apoptosis induced by METH. Oxytocin receptor activation is involved in the preventive effect of OT on METH-induced apoptosis in rat hippocampal neurons.

Keywords: methamphetamine, oxytocin, atosiban, oxytocin receptor, hippocampal neurons, apoptosis

\section{INTRODUCTION}

The expanding abuse of METH has become a serious public crisis because of its strong addictiveness. Excessive overuse of METH will cause various mental symptoms and also be harmful to the central nervous system. METH is a cationic lipophilic molecule that easily enters and stores in mitochondria, reduces mitochondrial membrane potential and interferes with the mitochondrial biosynthesis, such as ATP synthesis, resulting in increased levels of reactive oxygen species (ROS), ultimately leading to apoptosis (Lemasters et al., 1999; Wu et al., 2007). METH has been shown to cause cell death through dopa-mediated and glutamate-mediated pathways: After METH enters the dopaminergic matrix, it will promote the oxidation of dopamine to superoxide, and superoxide and nitric oxide react to form peroxynitrite, which leads to cell death; Dopamine can also promote the release of glutamate to activate NMDA receptor, resulting in increased production of nitric oxide and activation of the caspase cascade (Davidson et al., 2001). In addition, the ability of METH to penetrate the blood-brain barrier can make it easier to enter the brain to exert toxic effects (Srisurapanont et al., 2003; Shah and Kumar, 2016; Kish et al., 2017). However, the neurotoxic mechanism of METH is not completely 
understood. The possible mechanisms of METH-induced central nervous system injury include mitochondrial dysfunction, neuronal apoptosis, oxidative stress, and excitotoxicity (Murphy et al., 1999; Deng et al., 2002).

OT neurons are widely distributed in the central nervous system, and they perform as a central neurotransmitter or neuromodulator to participate in the regulation of reward, stress, learning, memory, social behavior and drug dependence (Smith et al., 2010; Churchland and Winkielman, 2012; Young, 2015). OT treatment has an inhibitory effect on METH primed reinstatement, while the vagus nerve and vasopressin V1A receptor mediate the inhibitory effect of OT on the selfadministration and seeking of METH in rats (Everett et al., 2018; Everett et al., 2020; Everett et al., 2021). A trial showed that OT may safely improve treatment attendance of patients with METH use disorder (Stauffer et al., 2020). After treatment with OT, it was found that the activity of hippocampal neurons was significantly improved either it was detected immediately after oxygen deprivation or after reoxygenation for $6 \mathrm{~h}$ after oxygen deprivation (Ceanga et al., 2010). Repeated administration of OT can promote hippocampal cell proliferation and dendritic cell maturation (Sánchez-Vidaña et al., 2016). In addition, OT can reduce rotenone-induced apoptosis in striatum neurons, suggesting that OT can protect damaged neurons through anti-apoptotic pathways (Erbaş et al., 2012).

Both humans and rodents express oxytocin receptor (OTR) in the brain. There're studies supporting that oxytocin receptor express much in the dorsal cortex, anterior olfactory nucleus, limbic system and hypothalamic nucleus of adult rats (Insel and Shapiro, 1992; Barberis et al., 2010; Kremarik et al., 2010; Tribollet et al., 2010). OT in the central nervous system can exert a variety of physiological functions through oxytocin receptor. OT can alter the effects of stress on synaptic plasticity and spatial memory in the rat hippocampus by oxytocin receptor (Tomizawa et al., 2003; Sun-Young et al., 2015). Previous studies have found that OT could significantly inhibit the formation of $\mathrm{METH}$-induced conditioned place preference (CPP) and the recurrence of CPP caused by restraint stress. These effects can be prevented by atosiban (ATO), oxytocin receptor antagonist (Qi et al., 2009). Previous in vitro study indicated OT offered protectiveness in the condition of cerebral ischemia and oxygen-rich hippocampal neurons and all these could be prevented by ATO (Ceanga et al., 2010). Combined with all above, we consider that OT may have neuroprotective effects associated with oxytocin receptor.

\section{MATERIALS AND METHODS}

\section{Materials}

METH was obtained from Criminal Investigation Institute of Liaoning Province. OT was obtained from Key Organics. Phosphate buffer saline (PBS) was obtained from Hyclone. Atosiban, Dimethyl sulfoxide (DMSO), 4', 6-diamidino-2phenylindole (DAPI), Poly-L-lysine and MTT were obtained from Sigma-Aldrich. B27 supplement, Neurobasal Medium, Fetal Bovine Serum (FBS), 0.25\% Trypsin-EDTA, DMEM/F12 medium and penicillin/streptomycin were obtained from Gibco. Mitochondrial membrane potential assay kit with JC-1, ROS Assay Kit, BCA protein assay kit, Alexa Fluor 488, Goat AntiRabbit lgG and Goat Serum were obtained from Beyotime Biotechnology. Horseradish peroxidase (HRP)-goat anti-mouse IgG and HRP-goat anti-rabbit IgG were obtained from Nakasugi Golden Bridge. Anti-Oxytocin Receptor and anti-beta III Tubulin antibodies were obtained from Abcam. Bax, CREB, AntiPhospho-CREB (P-CREB), Anti-P44/42MAPK (ERK1/2), Anti-Phospho-P44/42MAPK (P-ERK1/2), Anti-Caspase-3 and anti-Cleaved Caspase- 3 antibodies were obtained from Cell Signaling Technology. Anti-Bcl-2 Polyclonal antibody was obtained from Proteintech. Anti-beta-actin antibody was obtained from Santa Cruz Biotechnology. Anti-GAPDH antibody was obtained from Hangzhou Xianzhi Biological Technology Co., Ltd.

\section{Animals and Culture of Primary Hippocampal Neurons}

Male and female Sprague Dawley rats (250-280 g) were used to obtain neonatal rats were from Liaoning Changsheng Biotechnology Co., Ltd. Primary hippocampal neurons were prepared as previously described with minor modifications (Zhang et al., 2010). Briefly, hippocampal regions were removed from Sprague Dawley rats which were neonatal within $24 \mathrm{~h}$ in $\mathrm{Ca}^{2+}$ and $\mathrm{Mg}^{2+}$ free Hank's balanced salt solution under a stereo microscope in a sterile environment. After the hippocampus tissue was cut into small pieces by ophthalmological scissors, an appropriate amount of $0.25 \%$ Trypsin-EDTA was added to the shredded hippocampus and then digested in a $37^{\circ} \mathrm{C}$ water bath for $15 \mathrm{~min}$. Trypsin digestion was then stopped by adding an appropriate amount of DMEM/ F12 medium containing 10\% FBS and discard the supernatant. Add fresh DMEM/F12 containing 10\% FBS culture medium and gently blow the hippocampus tissue into a single cell with a hot-polished plastic pipette. After standing for about $1 \mathrm{~min}$, the supernatant cell suspension was filtered through a 200 mesh cell sieve to prepare a single cell suspension. Aspirate the mixed cell suspension for cell counting. The cell density was adjusted to $5 \times 10^{5}$ cells $/ \mathrm{mL}$ and inoculated into a culture plate coated with $0.01 \%$ poly-lysine in advance, gently mixed and cultured in a humidified $95 \%$ air, $5 \% \mathrm{CO}_{2}$ incubator. After $4 \mathrm{~h}$ of culture, the culture medium was replaced with a medium containing $86 \%$ Neurobasal medium, 10\% FBS, 2\% B27, 1\% glutamine stock solution, and $1 \%$ double antibody (penicillin, streptomycin). After that, half of the culture solution was replaced every $2 \mathrm{~d}$, and neurons cultured for $7-10 \mathrm{~d}$ were selected for subsequent experiments. The rats were used in this study and the cultivation protocol of primary hippocampal neurons were reviewed by the Animal Ethics Committee of Shenyang Pharmaceutical University, and the regulations were consistent with the Guideline for the Care and Use of Laboratory Animals published by the National Institutes of Health. 


\section{Purity Identification of Hippocampal Neurons}

Neuron purity were identified as described previously (Zhang et al., 2010). Adding appropriate amount of 4\% PFA fixed hippocampal neurons for $20 \mathrm{~min}$. Then cells were permeabilized with $0.03 \%$ Triton X-100 for $10 \mathrm{~min}$, block with $5 \%$ goat serum for $1 \mathrm{~h}$ at room temperature. Incubate with $0.1 \%$ beta-Tubulin III diluted in PBS at $4^{\circ} \mathrm{C}$ overnight and rinse with phosphate buffer saline with $0.1 \%$ Tween-20 (PBST). 0.5\% Alexa Fluor 488-labeled goat anti-rabbit secondary antibody was added and incubated for $1 \mathrm{~h}$ at room temperature in the dark, then rinsed with an appropriate amount of PBST. Add DAPI staining in the dark for $10 \mathrm{~min}$, discard the stain, and add a proper amount of PBST to rinse. After adding an appropriate amount of PBST to each well, the cells were observed using an inverted fluorescence microscope.

\section{Drug Treatment}

The primary hippocampal neurons were then randomly divided into six groups. The control cells were cultured for $24 \mathrm{~h}$ in a medium without drug, and the cells in OT $(0.01-1 \mu \mathrm{M})$ group, METH $(1-8 \mathrm{mM})$ group and ATO $(0.01-1 \mu \mathrm{M})$ group were cultured for $24 \mathrm{~h}$ in a drug-containing medium. OT $+\mathrm{METH}$ group and ATO + OT + METH group were pre-incubated with optimal concentration of OT $(1 \mu \mathrm{M})$ and/or ATO $(1 \mu \mathrm{M})$ for $2 \mathrm{~h}$ before treatment with METH, and then treated with METH $(4 \mathrm{mM})$ for $24 \mathrm{~h}$. After drug treatment, cells in each group were tested for cell viability by MTT assay. ROS, mitochondrial membrane potential, Cleaved Caspase- 3 and p-ERK1/2 were detected by immunofluorescence. Bcl-2, Bax, Cleaved Caspase-3, Caspase-3, CREB, P-CREB, ERK1/2, P-ERK1/2 and OTR were detected by western blotting.

\section{Cell Viability Assay}

Hippocampal neurons were cultivated in 48 -well plates for $7 \mathrm{~d}$. Assay for cell viability refer to the literature (Chang et al., 1998). Hippocampal neurons cultured for $7 \mathrm{~d}$ were incubated with drugs for a certain period of time at $37^{\circ} \mathrm{C}$, and four replicate wells were set in each group. Fresh culture medium and a final concentration of $\quad 0.25 \mathrm{mg} / \mathrm{ml} \quad 3$-(4,5-dimethylthiazol-2-yl)-2,5-diphenyltetrazolium bromide (MTT) solution were added during the test, and the cells were incubated in a $37^{\circ} \mathrm{C}$ incubator $(95 \%$ air, $5 \% \mathrm{CO}_{2}$ ) for $4 \mathrm{~h}$. The medium was then aspirated, an equal volume of DMSO solvent was added and mixed with a micro-vibrator for $10 \mathrm{~min}$. Absorbances were read at $570 \mathrm{~nm}$ using a microplate reader. The experiment was repeated for 6 times. Viable cells (cell viability, CV) were measured in percentage with respect to the following formula:

$$
C V(\%)=(\mathrm{OD}(\text { sample })) /(\mathrm{OD}(\text { Control })) \times 100 \%
$$

\section{Detection of Reactive Oxygen Species in Neurons}

Fluorescence intensity changes of Dichloro-dihydro-fluorescein diacetate (DCFH-DA) could quantitatively detect intracellular
ROS levels. DCFH-DA itself has no fluorescence and could pass through the cell membrane freely. After entering the cell, it could be hydrolyzed by intracellular esterase to form DCFH. DCFH does not penetrate the cell membrane, making it easy for the probe to be loaded into the cell. DCFH could be converted to DCF after exposure to ROS. By measuring the fluorescence of DCF, the level of intracellular ROS could be known, and the fluorescence intensity is directly proportional to the intracellular ROS level. Rosup is a drug that raises intracellular ROS. Rosup $(100 \mu \mathrm{M})$ was added to the untreated cell culture plates and incubated for $30 \mathrm{~min}$ in a $37^{\circ} \mathrm{C}$ incubator. The drug-treated medium was discarded, and fluorescent probe DCFH-DA $(10 \mu \mathrm{M})$ was added to the drug-treated, Rosup-treated cells in a $37^{\circ} \mathrm{C}$ incubator for $20 \mathrm{~min}$ in the dark. The loaded cells were washed with serum-free medium to remove residual probes. Then an appropriate amount of cell culture medium was added to the cells, observed with a confocal microscope (Nikon, C2 Plus).

\section{Detection of Mitochondrial Membrane Potential}

When the mitochondrial membrane potential is high, $5,5^{\prime}, 6,6^{\prime}$ Tetrachloro-1, $1^{\prime}, 3,3^{\prime}$-tetraethyl-imidacarbocyanine iodide (JC-1) aggregates in the matrix of mitochondria in the form of polymer, which could produce red fluorescence; when the mitochondrial membrane potential was low, JC- 1 could not accumulate in the matrix of mitochondria, only exist in the cytosol, JC-1 was a monomer at this time, which could produce green fluorescence. The relative proportion of commonly used red-green fluorescence was a measure of the proportion of mitochondrial depolarization. Decreased mitochondrial membrane potential was a hallmark feature of early apoptosis. CCCP $(10 \mu \mathrm{M}$, a drug that lowers mitochondrial membrane potential) was added to untreated cells and incubated for $20 \mathrm{~min}$ in a $37^{\circ} \mathrm{C}$ incubator. The drug-treated and CCCP-treated hippocampal neurons were gently washed once with PBS and then mixed with the culture solution with JC-1 staining solution and the cells were incubated for $20 \mathrm{~min}$ in a $37^{\circ} \mathrm{C}$ incubator. After the incubation, the culture solution was aspirated and washed twice with pre-cooled JC-1 staining buffer. Then an appropriate amount of cell culture medium was added to the cells, observed with a confocal microscope (Nikon, C2 Plus).

\section{Western Blotting}

The cells were lysed with an appropriate amount of ice-cold RIPA lysis buffer (97\% RIPA strong lysate, $1 \%$ benzylsulfonyl fluoride, $\left.1 \% \mathrm{NaF}, 1 \% \mathrm{Na}_{3} \mathrm{VO}_{4}\right)$, then the cells were disrupted with a $1 \mathrm{ml}$ syringe and allowed to stand at low temperature for $30 \mathrm{~min}$. After the sample was cryopreserved, the BCA method was used to determine the total protein concentration, and then RIPA was used to adjust the total protein concentration of each group to the same concentration. Add loading buffer to each cell lysate, vortex and centrifuge to $\mathrm{mix}$ well, then heated at $95-100^{\circ} \mathrm{C}$ for $10 \mathrm{~min}$ to fully denature the protein. Proteins of each group of samples were separated using $10 \%$ SDS-polyacrylamide gels (SDS-PAGE). The separated proteins were transferred onto polyvinylidene fluoride 
A
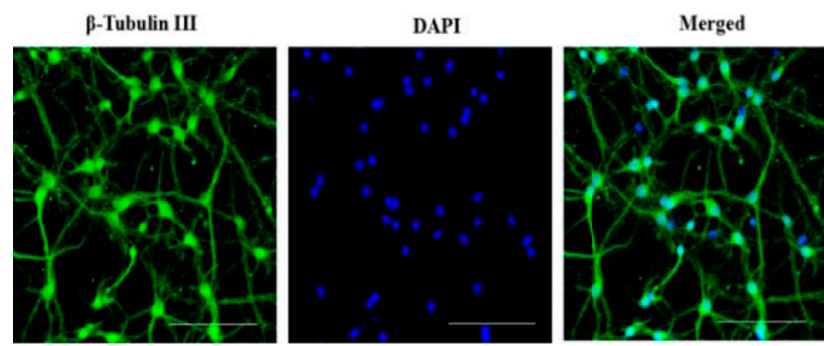

C

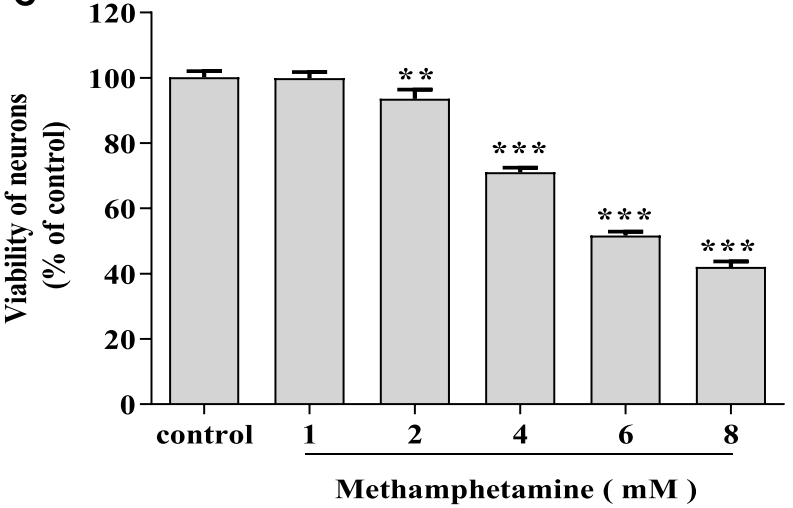

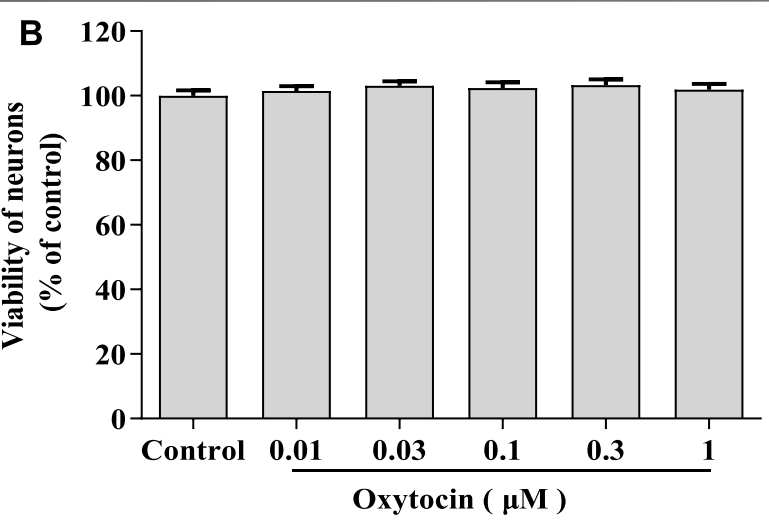

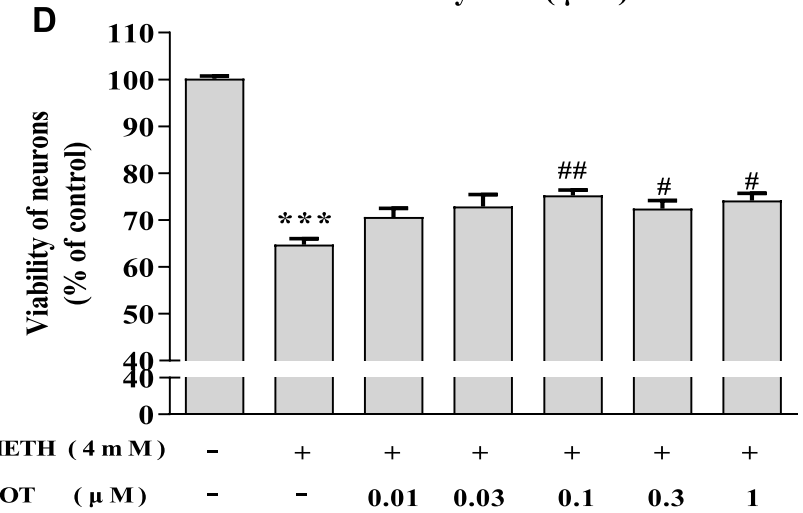

FIGURE 1 | OT attenuates the decrease in METH-induced hippocampal neuron survival. (A) Immunochemical identify of hippocampal neurons by fluorescence dyeing. Neurons were stained with Cytoskeleton (green) ( $\times 20$ objective, Scale bars $=50 \mu \mathrm{m})$. Nuclei were counter stained with DAPI (blue). (B) Hippocampal neurons were treated with OT $(0.01-1 \mu \mathrm{M})$ for $24 \mathrm{~h}$ (C) Hippocampal neurons were treated with METH (1-8 mM) for $24 \mathrm{~h}$. (D) Hippocampal neurons were pre-treated with OT $(0.01-1 \mu \mathrm{M})$ for $2 \mathrm{~h}$ and stimulated with METH $(4 \mathrm{mM})$ for $24 \mathrm{~h}$ before detected. All the values were shown as mean \pm SEM $(n=3) .{ }^{\star \star} p<0.01,{ }^{\star \star \star} p<0.001$ versus control groups; ${ }^{\#} p<0.05,{ }^{\# \#} p<0.01$ versus METH groups.

membranes. After blocking in 5\% skim milk, the membranes were incubated with primary antibodies including anti-Caspase-3 antibody (Cell Signaling, 9664T), anti-Cleaved Caspase-3 antibody (Cell Signaling, 9661S), Bax antibody (Cell Signaling, 2772T), CREB antibody (Cell Signaling, 9197S), Anti-PhosphoCREB (Cell Signaling, 9198S), Anti-ERK1/2 (Cell Signaling, 4695S), Anti-Phospho- ERK1/2 (Cell Signaling, 4370S), AntiOxytocin Receptor Antibody (Abcam, ab217212), BCL-2 Polyclonal Antibody (Proteintech, 12789-1-AP), Beta-actin Antibody (Santa Cruz Biotechnology, sc-47778), GAPDH Antibody (Hangzhou Xianzhi Biological Technology Co., Ltd., $\mathrm{AB}-\mathrm{MM}$ 001). The membranes were incubated with horseradish peroxidase-conjugated secondary antibodies $(1: 5,000)$ at room temperature. Finally, place the membranes on the blackboard and add an appropriate amount of ECL illuminant to expose it on the imager (Bio-Tanon, Tanon-2500R). The experiments were replicated three times.

\section{Statistical Analysis}

All data were statistically analyzed using SPSS 21.0 software. Western blot images and fluorescent images were processed using image J software and IPP 6.0 software. The data was plotted using GraphPad Prism 6.02 software. All values were expressed as means \pm SEM. One-Way ANOVA was used to determine the overall significant difference between groups. The LSD test was used when the variance was equal, and the Dunnett- $t$ test was used when the variance was not observed. A value of $p<0.05$ was considered as statistically significant.

\section{RESULTS}

\section{Oxytocin Attenuates Methamphetamine-Induced Cytotoxic Effect in Hippocampal Neurons}

Primary hippocampal neurons cultured in vitro for $7 \mathrm{~d}$ were subjected to purity analyses using immunofluorescence staining with beta-Tubulin III antibody and DAPI. Purity of hippocampal neurons was $90 \%$ (Figure 1A), which could be used in subsequent experiments as described ( $\mathrm{Xu}$ et al., 2014). As shown in Figure 1C, hippocampal neurons were treated with METH (1-8 $\mathrm{mM})$ and the cell viability gradually decreased along with the increase of METH concentration. Compared with the control, $4 \mathrm{mM}$ METH significantly reduced the viability of hippocampal neurons, which are similar to METH concentration reported in 


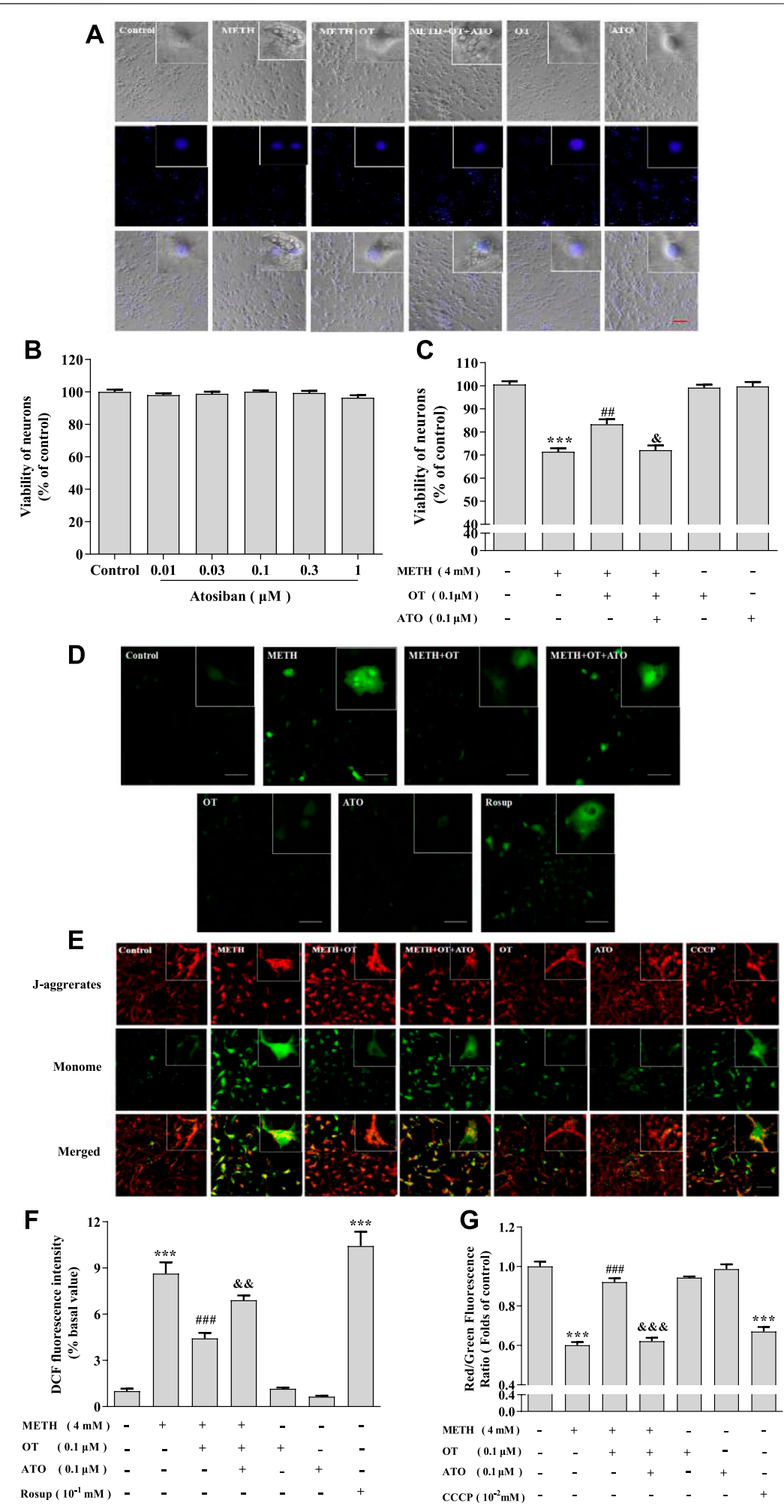

FIGURE 2 | Oxytocin receptor participated in the prevention of METH -induced cytotoxicity in hippocampal neurons. (A) Hippocampal were pre-treated with OT and ATO for $2 \mathrm{~h}$ and stimulated with METH for $24 \mathrm{~h}$. The cells were observed under a fluorescence microscope. ( $\times 20$ objective; Scale bar $=50 \mu \mathrm{m})$. (B) Hippocampal neurons were treated with ATO $(0.01-1 \mu \mathrm{M})$ for $24 \mathrm{~h}$. (C) Hippocampal neurons were pre-treated with OT $(0.1 \mu \mathrm{M})$ and ATO $(0.1 \mu \mathrm{M})$ for $2 \mathrm{~h}$ and stimulated with METH $(4 \mathrm{mM})$ for $24 \mathrm{~h}$ before detected. (D,F) Cells were observed by confocal microscope after stained with the Fluorescent dye DCFH-DA, DCF (Green fluorescence) 
FIGURE 2 | measures ROS production. (×20 objective; Scale bar = $50 \mu \mathrm{m}$ ). (E,G) Cells were observed by confocal microscope after stained with the Fluorescent dye JC-1, JC-1 polymer/JC-I monomer (red/green fluorescence) measures the level of mitochondrial membrane potential. $(\times 20$ objective; Scale bar $=50 \mu \mathrm{m})$. The data were

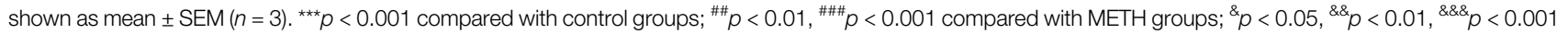
compared with METH + OT groups.
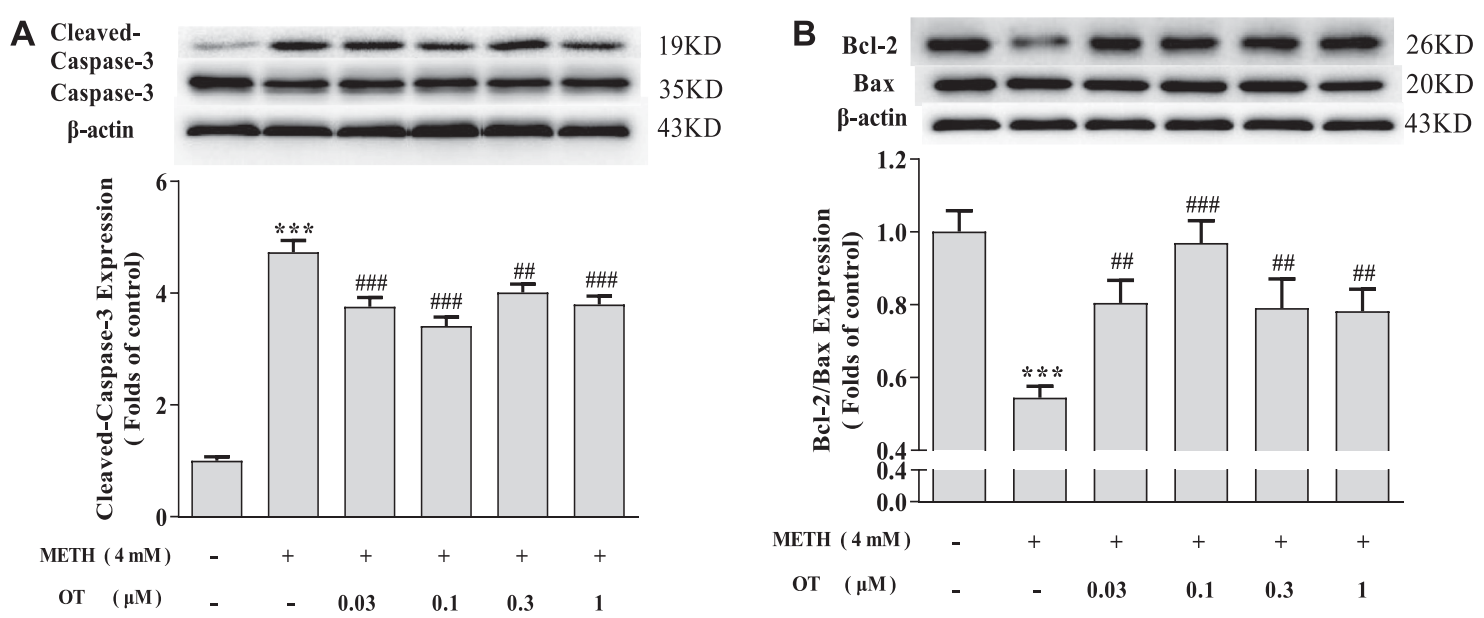

FIGURE 3 | Effects of OT on the expression of apoptosis related proteins changed by METH in hippocampal neurons. (A, B) Hippocampal neurons were pretreated with OT $(0.03-1 \mu \mathrm{M})$ for $2 \mathrm{~h}$ and stimulated with METH $(4 \mathrm{mM})$ for $24 \mathrm{~h}$ by western blotting. The data were shown as mean \pm SEM $(n=3)$. ${ }^{\star \star *} p<0.001 \mathrm{compared}$ with control groups; ${ }^{\#} p<0.01,{ }^{\# \# \#} p<0.001$ compared with METH groups.

the literature (Qiao et al., 2014). Therefore, $4 \mathrm{mM} \mathrm{METH}$ was selected as the subsequent model concentration. MTT assay indicated that OT $(0.01-1 \mu \mathrm{M})$ did not exhibit a toxic effect on the neurons (Figure 1B). Afterwards, the neurons were pretreated with OT $(0.01-1 \mu \mathrm{M})$ for $2 \mathrm{~h}$, followed by a $24 \mathrm{~h}$ ' stimulation with METH $(4 \mathrm{mM})$. Figure 1D showed that OT $(0.1-1 \mu \mathrm{M})$ significantly attenuated the decrease in the vitality of hippocampal neurons induced by METH.

\section{Oxytocin Receptor Activation Is Involved in the Prevention of Methamphetamine-Induced Cytotoxicity in Hippocampal Neurons}

It has been reported that ATO can antagonize the neuroprotective effect of OT on an equal dose (Ceanga et al., 2010; Kaneko et al., 2016). In order to clarify the role of oxytocin receptor, we carried out an experiment designed as follow: ATO $(0.1 \mu \mathrm{M})$ and OT $(0.1 \mu \mathrm{M})$ were pre-incubated for $2 \mathrm{~h}$, and then incubated with METH ( $4 \mathrm{mM})$ for $24 \mathrm{~h}$. MTT assay indicated that ATO $(0.01-1 \mu \mathrm{M})$ did not show a toxic effect (Figure 2B). As shown in Figure 2A, OT could inhibit the enlargement of the cell body and the shrinkage of the nucleus induced by METH and this effect could be prevented by ATO. Similar results could also be obtained from MTT experiment (Figure 2C). We tested whether this effect was reflected in other cytotoxicity indicators of METH, including ROS levels and mitochondrial membrane potential levels. As result, OT pre-incubation prevented the decrease of mitochondrial membrane potential and the increased of ROS in hippocampal neurons induced by METH. Pre-incubation with ATO significantly prevented these changes (Figures 2D-G). These results indicate that oxytocin receptor participated in the prevention of METH-induced cytotoxicity in hippocampal neurons.

\section{Oxytocin Attenuates}

Methamphetamine-Induced Changes on Apoptotic Proteins in Hippocampal Neurons As shown in Figures 3A,B, METH increased the expression of Cleaved-Caspase-3 and decreased Bcl-2/Bax in hippocampal neurons. Pre-treatment with OT significantly attenuated the up-regulation of Cleaved-Caspase-3 expression and the downregulation of $\mathrm{Bcl}-2 / \mathrm{Bax}$ expression induced by $\mathrm{METH}$.

\section{Oxytocin Attenuates}

\section{Methamphetamine-Induced Apoptosis via Oxytocin Receptor in Hippocampal Neurons} As shown in Figures $\mathbf{4 A - C}$, OT pre-incubation attenuated hippocampal neuronal nuclear shrinkage partial nuclear fragmentation and the up-regulation of Cleaved-Caspase-3 expression induced by METH. Pre-incubation with ATO significantly prevented these effects of OT. Similarly, Preincubation with ATO significantly reduced the expression of $\mathrm{Bcl}-2 / \mathrm{Bax}$ compared to $\mathrm{METH}+\mathrm{OT}$ group (Figure 4D). 
A
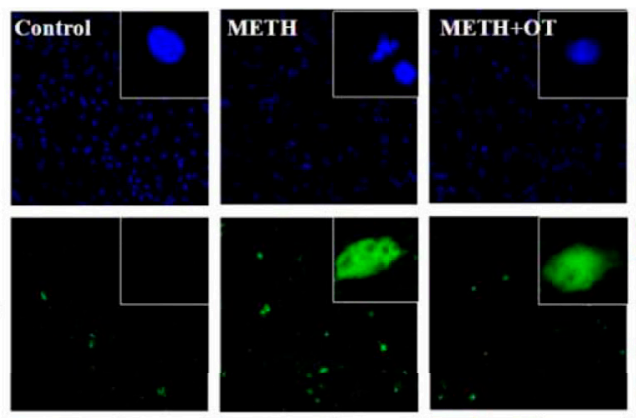

CleavedCaspase-3
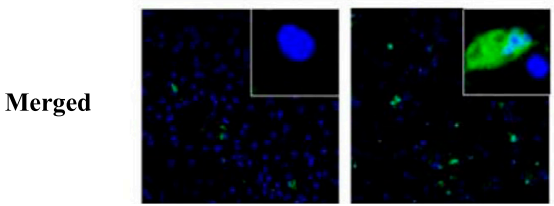
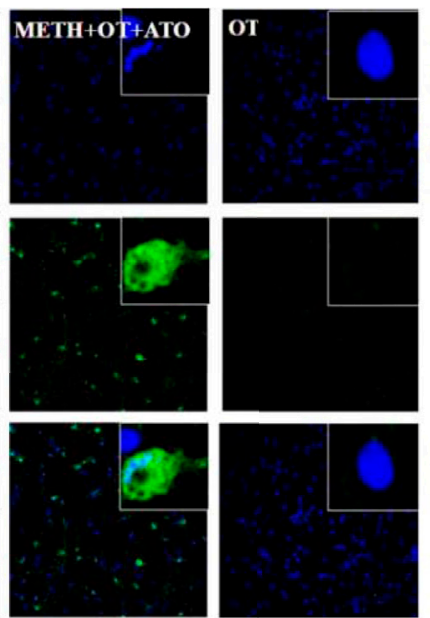
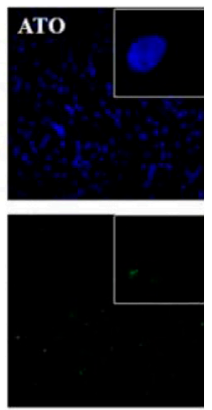

B

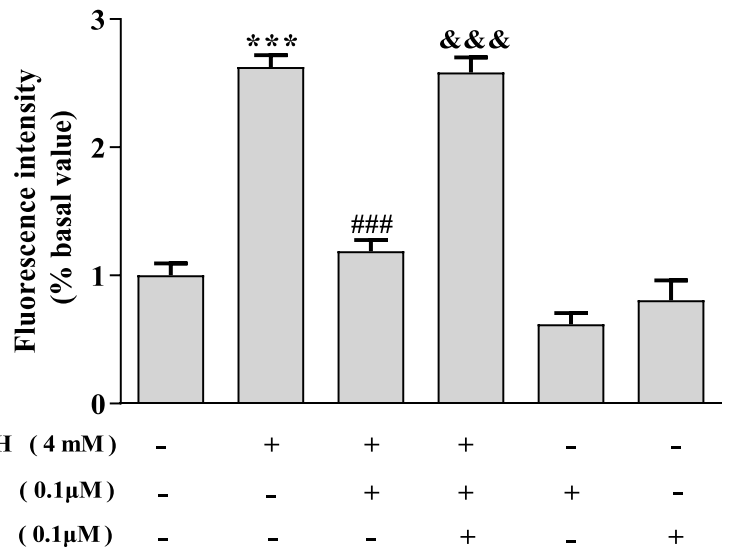

C Cleaved-

Caspase-3

Caspase-3

$\beta$-actin

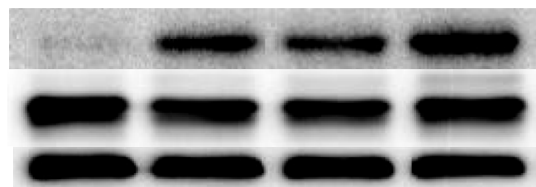

19KD

$35 \mathrm{KD}$

$43 \mathrm{KD}$
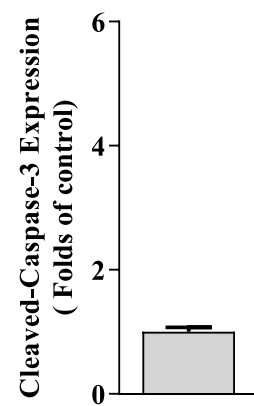

$\stackrel{* * *}{1}$
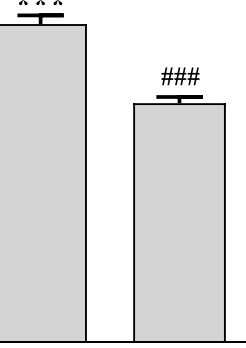

METH ( 4 mM)

OT $(0.1 \mu \mathrm{M})$

ATO $(0.1 \mu \mathrm{M})$
\&\&
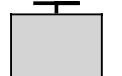

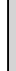
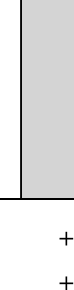
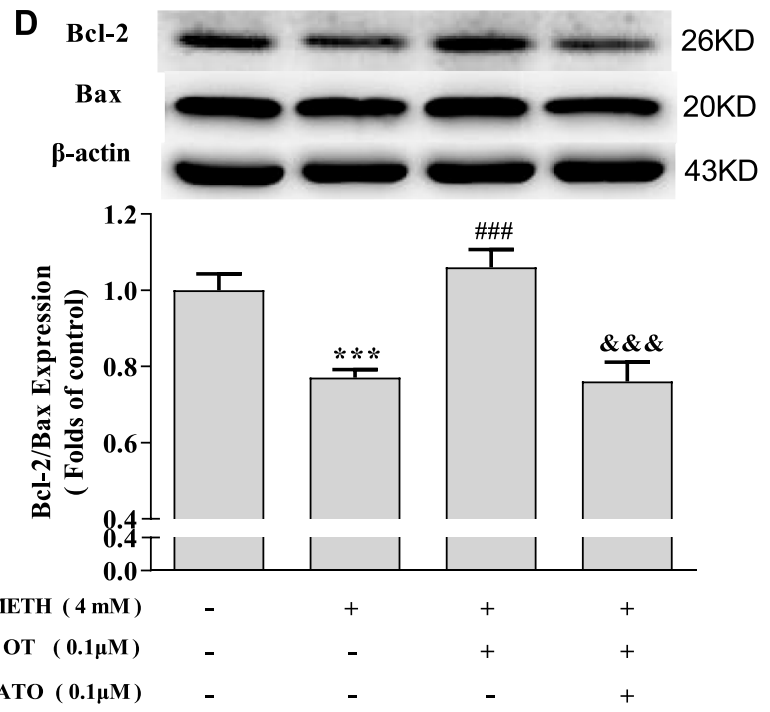

FIGURE 4 | The effect of pre-incubation ATO and OT on METH-induced changes in the expression of Cleaved-Caspase-3 and Bcl-2/Bax. (A, B) Hippocampal neurons were pre-treated with OT $(0.1 \mu \mathrm{M})$ and ATO $(0.1 \mu \mathrm{M})$ for $2 \mathrm{~h}$ and stimulated with METH for $24 \mathrm{~h}$. The panels in the columns marked "Merged" are merged images of the panels in the two left columns. ( $\times 20$ objective; Scale bar $=50 \mu \mathrm{m})$. Each image by (IOD sum)/(area sum) represent the Cleaved-caspase -3 levels. (C-D) Hippocampal neurons were pre-treated with OT $(0.1 \mu \mathrm{M})$ and ATO $(0.1 \mu \mathrm{M})$ for $2 \mathrm{~h}$ and stimulated with METH $(4 \mathrm{mM})$ for $24 \mathrm{~h}$ by western blotting. The data were shown as mean \pm SEM $(n=3) .{ }^{* *} p<0.001$ compared with control group; ${ }^{* \# \#} p<0.001$ compared with METH group; ${ }^{8 \&} p<0.01,{ }^{8 \& \&} p<0.001$ compared with METH + OT group. 


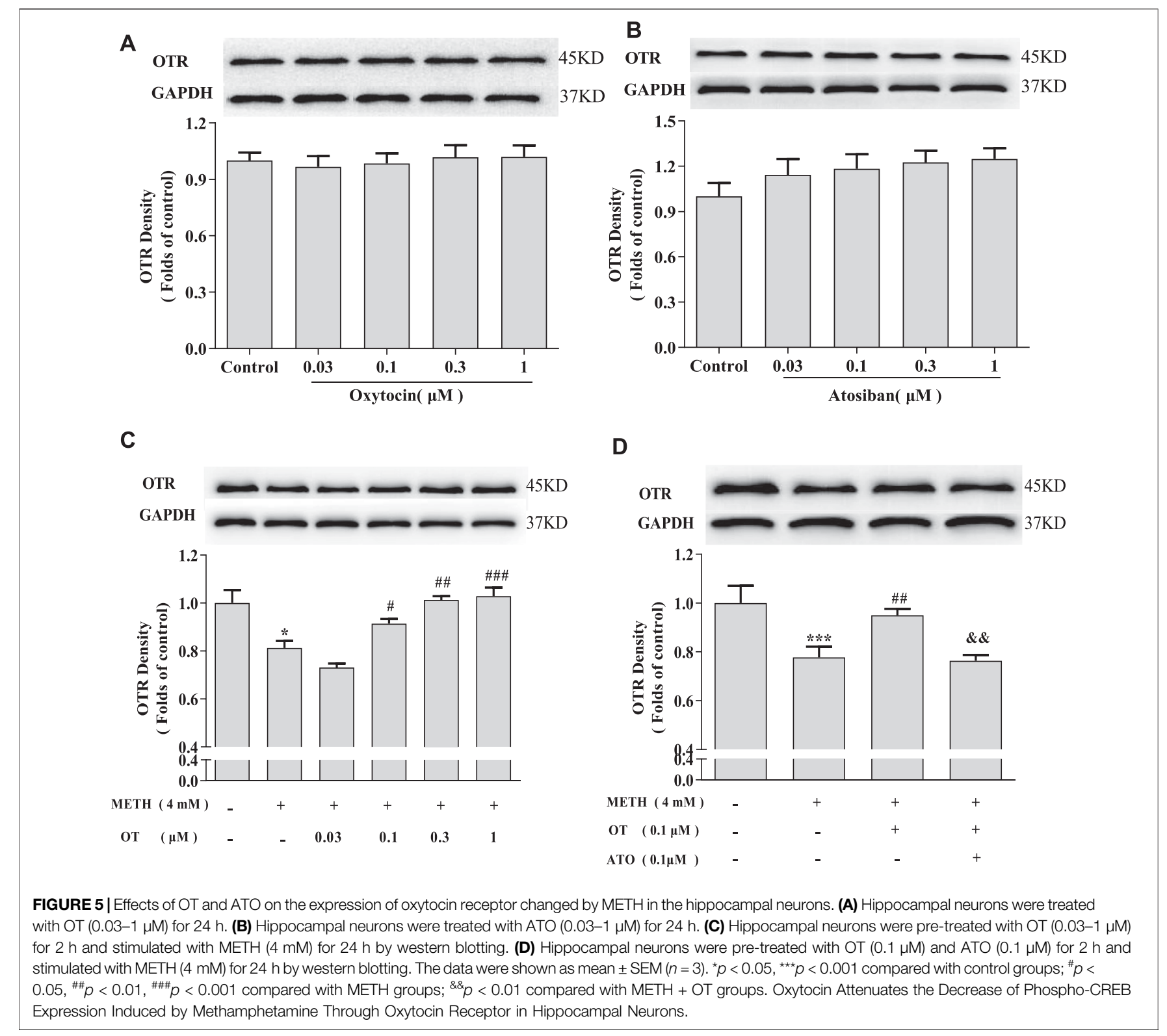

These results indicate that OT could significantly attenuate METH-induced apoptosis via oxytocin receptor in hippocampal neurons.

\section{Oxytocin Prevents \\ Methamphetamine-Induced Oxytocin Receptor Density Reduction in Hippocampal Neurons}

In order to explore how OT influences on oxytocin receptor in the injured hippocampal neurons, we investigated the changes of the density of oxytocin receptor via western blotting. As shown in Figures 5A,B, OT and ATO had no significant effect on the density of oxytocin receptor in hippocampal neurons in our experiment condition. Figures 5C,D showed that METH $(4 \mathrm{mM})$ significantly decreased the density of oxytocin receptor. Pre-incubation with OT $(0.1-1 \mu \mathrm{M})$ prevented the decrease of oxytocin receptor density induced by METH. Preincubation with ATO significantly prevented this effect.

METH significantly increased the expression of $\mathrm{p}$-ERK $1 / 2$ in hippocampal neurons compared with the control group, whereas pre-administration of OT and ATO could not attenuate the increase of $\mathrm{p}$-ERK1/2 expression induced by METH (Figures 6B,C). Pre-treatment with OT significantly attenuated the decrease of $\mathrm{p}$-CREB induced by METH (Figure 6D). Pretreatment with ATO could prevent this effect (Figure 6D). These results indicate that OT could attenuate METH-induced p-CREB expression reduction through the oxytocin receptor in hippocampal neurons. 


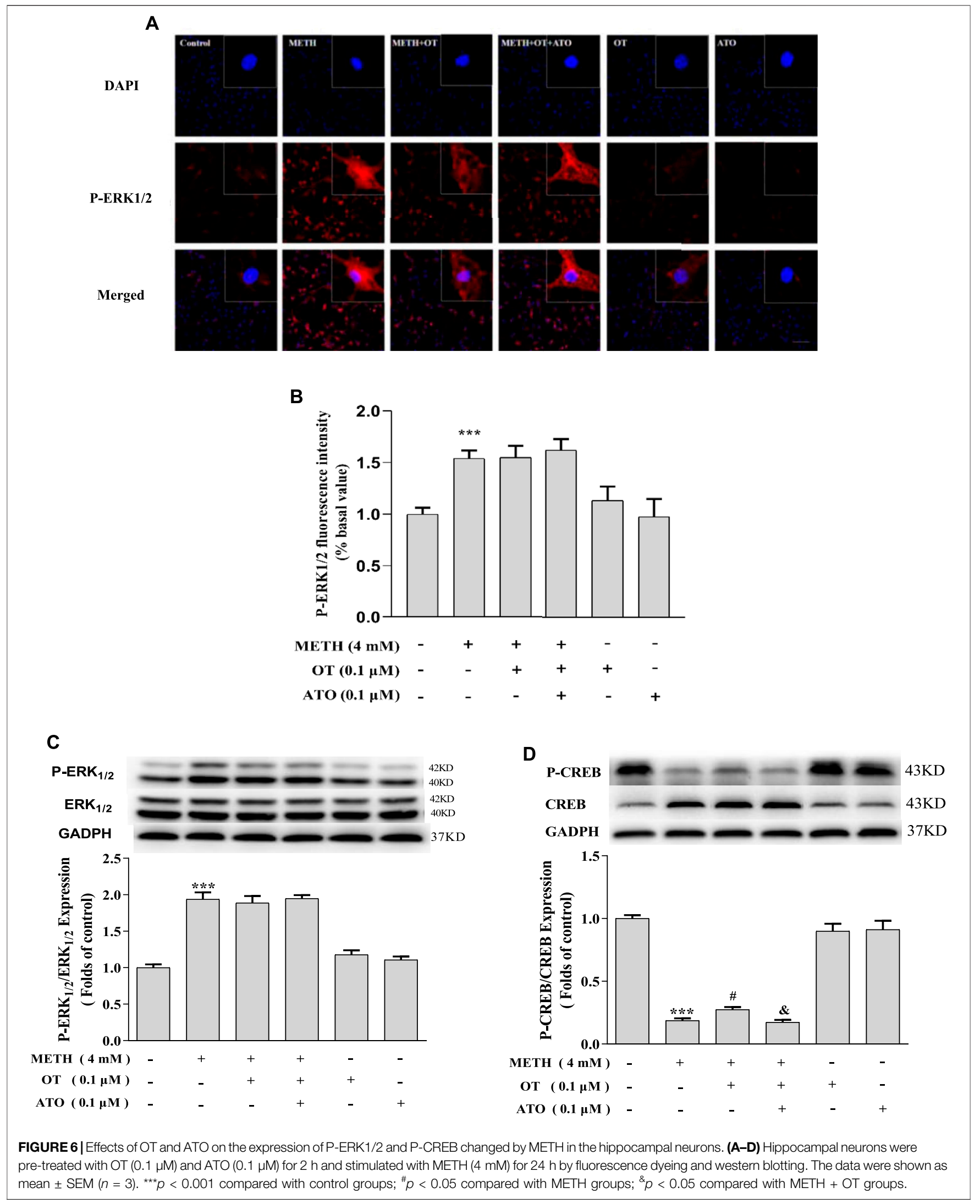




\section{DISCUSSION}

Studies have shown that METH could cause DNA strand breaks, chromatin condensation and nuclear lysis, indicating that METH could induce apoptosis (Cadet et al., 1997). Previously studies have demonstrated that OT has inhibitory effects against METHinduced conditioned place preference (CPP) and the recurrence of CPP caused by restraint stress, which could be prevented by ATO (Qi et al., 2009). However, there are few researches on the protective mechanism of OT on METH-induced apoptosis in hippocampal neurons. Therefore, we hypothesized that if oxytocin receptors are expressed in hippocampal neurons, OT may inhibit or attenuate METH-induced apoptosis by activating oxytocin receptor. As expected, our results indicate that oxytocin receptor activation is involved in the preventive effect of OT on $\mathrm{METH}$-induced apoptosis in rat hippocampal neurons.

The hippocampus is part of the most studied in the central nervous system of mammals. Changes in the structure and function of the hippocampus have been demonstrated to play an extremely important role in many diseases. Primary cultured hippocampal neurons can reflect their state in vivo to a certain extent and have been widely used in neuroscience study. The cytotoxicity of METH could lead to apoptosis, and a decrease in cell viability can be measured in vitro. MTT results showed that $4 \mathrm{mM} \mathrm{METH}$ could significantly reduce the viability of hippocampal neurons. Literature has shown that in vitro experiments, $3 \mathrm{mM}$ METH could damage cells through a process involving DNA fragmentation between nucleosomes and chromatin condensation, which is consistent with the process of apoptosis (Cadet et al., 1997; Qiao et al., 2014). It shows that in vitro experiments, acute treatment of cells with high doses of METH could induce cell apoptosis, and cell death is not caused by the non-specific toxicity of the drug. MTT and morphological results showed that ATO could prevent the protective effect of OT on hippocampal neurons. It shows that OT could attenuate the decreased vitality of hippocampal neurons caused by METH through oxytocin receptor. On the other hand, the decrease of mitochondrial membrane potential and ROS have been shown to play an import role in METH-induced toxicity (Ramkissoon and Wells, 2015). OT and other antioxidants can resist the decrease of mitochondrial membrane potential induced by METH (Wagner et al., 1985; De Vito and Wagner, 1989; Wu et al., 2006). For the above, we next examined ROS levels and the changes in mitochondrial membrane potential in each group of cells. Consistent with our expectations, we confirmed that OT could prevent the decrease of mitochondrial membrane potential and the increase of ROS induced by METH in hippocampal neurons. But all these effects could be prevented by ATO.

METH promotes the release of glutamate after entering neurons, and activates NMDA receptor to increase the production of ROS and nitric oxide. In addition, METH enters the mitochondria to increase the $\mathrm{pH}$ of the inner membrane matrix, thereby reducing the activity of ATP synthase, resulting in a decrease in the ability of mitochondria to maintain membrane potential. At the same time, it promotes the release of large amounts of $\mathrm{Ca}^{2+}$ from the mitochondrial permeability transition pore, activates nitric oxide, reduces the amount of $\mathrm{Bcl}-2$, and activates the caspase cascade to induce apoptosis (Davidson et al., 2001). Previous studies have shown that OT could inhibit the decrease of $\mathrm{Bcl}-2$ and the increase of $\mathrm{Bax}$ in the striatum induced by rotenone (Taylor et al., 2008). Bcl-2/Bax was usually used to indicate mitochondrial permeability of damaged cells (Li et al., 2003; Newhouse et al., 2004). Western blotting results showed that METH significantly decreased the expression of Bcl-2 but did not alter the expression of Bax protein. We speculated that Bax protein expression is different due to the presence of drug concentration, cell type and duration of action. Despite this, METH significantly decreased the expression of $\mathrm{Bcl}-2 / \mathrm{Bax}$ and increased the expression of Cleaved-Caspase-3, indicating that METH could promote hippocampal neuronal apoptosis. Pre-treatment with OT significantly attenuated the pro-apoptotic effect of METH. Similar to MTT assay, ATO could prevent this effect of OT. These results further demonstrated that OT can exert an anti-apoptotic effect through oxytocin receptor.

To investigate how OT exerts neuroprotective effects through oxytocin receptor, we first studied the density of oxytocin receptor in each group. Our results show that OT and ATO had no significant effects on the density of oxytocin receptor in hippocampal neurons. Additionally, METH significantly reduced the density of oxytocin receptor. OT pre-treatment prevented $\mathrm{METH}$-induced reduction of oxytocin receptor density in rat hippocampal neurons, and pretreatment with ATO prevented this effect. In vivo studies have shown that chronic intraperitoneal injection of $\mathrm{METH}$ in male CD1 mice can cause an up-regulation of oxytocin receptor density in specific areas of the amygdala and hypothalamus, but not in the nucleus accumbens and caudate shell. These changes may be the result of long-term use of METH caused by the neurological adaptation of oxytocin receptor system in related brain areas, but the significance of the changes in oxytocin receptor in these brain areas is not fully understood (Zanos et al., 2014). Our results indicate that METH also caused changes on oxytocin receptor in rat hippocampal neurons cultured in vitro, and OT could prevent these changes. This may be related to part of the behavior of OT in the treatment of METH addiction in rodents in vivo studies. In fact, studies have shown that the oxytocin receptor mediates the inhibitory effect of OT on the recurrence of conditioned place preference caused by $\mathrm{METH}$-induced conditioned place preference and restraint pressure (Qi et al., 2009). At least our results show that OT treatment is beneficial to METHinjured neurons, and provides certain in vitro theoretical support for OT treatment of METH-induced nerve damage. At the same time, in order to study whether OT participates in certain cellular pathways through oxytocin receptor to affect the apoptosis caused by METH in rat hippocampal neurons. We also explored whether the ERK1/2CREB pathway is involved in the neuroprotective effects of OT.

ERK1/2 is the first-found MAPKs protein kinase in mammals (Cooper et al., 1982). In most mammalian MAPKs cascade, ERK1/2 pathway is mainly activated by stress stimuli and growth factors. ERK1/2 pathway is generally involved in cell survival (Giancotti, 1997). However, depending on the type of stimulus, ERK1/2 has also been reported to be associated with cell death through apoptosis and a second type of programmed cellular mechanism (Ulivi et al., 2010). Some studies have found that the neurotoxicity caused by carmustine is partly caused by activation of ERK1/2, and Chlorpyrifos can activate ERK1/2 through ROS to cause nerve cell death, indicating that 
ERK1/2 activation can cause cytotoxic damage (An et al., 2011; Lee et al., 2012). ERK1/2 also have the potential to resist neurodegeneration by inhibiting caspase and the apoptotic pathway (Karmarkar et al., 2011). ERK1/2 activation could remarkably increase the phosphorylation of CREB, the elevated phosphorylation of CREB contributes to the activation of $\mathrm{Bcl}-2$, which functions as an anti-apoptotic protein, consequently preventing neuronal death (Meller et al., 2005). Similar to the previous results, OT attenuated the upregulation of $\mathrm{P}$-CREB expression induced by METH via oxytocin receptor. However, our results suggested that OT did not attenuate $\mathrm{METH}$-induced increase in P-ERK1/2 expression. It has been reported in the literature that other MAPKs signaling pathways such as P38 and JNK pathways are involved in methamphetamine-induced apoptosis. The use of P38 inhibitors could significantly attenuate the apoptosis of hippocampal neurons induced by METH (Zhu, et al., 2018). The use of JNK inhibitor 600,125 attenuated the METH-induced apoptosis in SH-SY5Y cells (Wang, et al., 2008). In this study, the specific mechanism needs to be further explored.

In conclusion, our study proved that OT could significantly attenuate $\mathrm{METH}$-induced apoptosis in rat hippocampal neurons and this protective effect involves activation of oxytocin receptor. Our results provide some theoretical basis for the protection of OT against neuronal damage induced by METH abuse.

\section{DATA AVAILABILITY STATEMENT}

The original contributions presented in the study are included in the article/Supplementary Files, further inquiries can be directed to the corresponding authors.

\section{REFERENCES}

An, J. M., Kim, S. S., Rhie, J. H., Shin, D. M., Seo, S. R. J. T., and Seo, J. T. (2011). Carmustine Induces Erk- and Jnk-dependent Cell Death of NeuronallyDifferentiated Pc12 Cells via Generation of Reactive Oxygen Species. Toxicol. Vitro 25 (7), 1359-1365. doi:10.1016/j.tiv.2011.05.006

Barberis, C., Audigier, S., Durroux, T., Elands, J., Schmidt, A., and Jard, S. (2010). Pharmacology of Oxytocin and Vasopressin Receptors in the central and Peripheral Nervous System. Ann. N. Y Acad. Sci. 652 (1), 39-45. doi:10.1111/j.1749-6632.1992.tb34344.x

Cadet, J. L., Ordonez, S. V., and Ordonez, J. V. (1997). Methamphetamine Induces Apoptosis in Immortalized Neural Cells: Protection by the Proto-Oncogene, Bcl-2. Synapse 25 (2), 176-184. doi:10.1002/(sici)1098-2396(199702)25:2<176:: aid-syn8 $>3.0$. co;2-9

Ceanga, M., Spataru, A., and Zagrean, A. M. (2010). Oxytocin Is Neuroprotective against Oxygen-Glucose Deprivation and Reoxygenation in Immature Hippocampal Cultures. Neurosci. Lett. 477 (1), 15-18. doi:10.1016/j.neulet.2010.04.024

Chang, J. Y., Chavis, J. A., Liu, L.-Z., and Drew, P. D. (1998). Cholesterol Oxides Induce Programmed Cell Death in Microglial Cells. Biochem. Biophysical Res. Commun. 249 (3), 817-821. doi:10.1006/bbrc.1998.9237

Churchland, P. S., and Winkielman, P. (2012). Modulating Social Behavior with Oxytocin: How Does it Work? what Does it Mean? Horm. Behav. 61 (3), 392-399. doi:10.1016/j.yhbeh.2011.12.003

Cooper, J. A., Bowen-Pope, D. F., Raines, E., Ross, R., and Hunter, T. (1982). Similar Effects of Platelet-Derived Growth Factor and Epidermal Growth Factor on the Phosphorylation of Tyrosine in Cellular Proteins. Cell 31 (1), 263-273. doi:10.1016/0092-8674(82)90426-3

\section{ETHICS STATEMENT}

The animal study was reviewed and approved by the Animal Ethics Committee, Shenyang Pharmaceutical University, China.

\section{AUTHOR CONTRIBUTIONS}

CL: Writing-original draft, Conceptualization, Writing-Review and Editing. HW: Writing-original draft, Data Curation, Methodology. MB: Writing-original draft. MW: Investigation. CC: Data Curation, Formal analysis. FB: Methodology. CW: Resources.

\section{FUNDING}

This study was supported by the National Natural Science Foundation of Liaoning Province (No: 20180550253), Scientific Research Foundation of the Education Department of Liaoning Province (2021), Scientific Research Staring Foundation for the Returned Overseas Scholars, Shenyang Pharmaceutical University (No: GGJJ2021101), and National Science and Technology Major Project of the Ministry of Science and Technology of China (No. 2018ZX09735005).

\section{SUPPLEMENTARY MATERIAL}

The Supplementary Material for this article can be found online at: https://www.frontiersin.org/articles/10.3389/fphar.2021.639571/ full\#supplementary-material

Davidson, C., Gow, A. J., Lee, T. H., and Ellinwood, E. H. (2001). Methamphetamine Neurotoxicity: Necrotic and Apoptotic Mechanisms and Relevance to Human Abuse and Treatment. Brain Res. Rev. 36 (1), 1-22. doi:10.1016/s0165-0173(01)00054-6

De Vito, M. J., and Wagner, G. C. (1989). Methamphetamine-induced Neuronal Damage: A Possible Role for Free Radicals. Neuropharmacology 28 (10), 1145-1150. doi:10.1016/0028-3908(89)90130-5

Deng, X., Cai, N.-S., Mccoy, M. T., Chen, W., Trush, M. A., and Cadet, J. L. (2002). Methamphetamine Induces Apoptosis in an Immortalized Rat Striatal Cell Line by Activating the Mitochondrial Cell Death Pathway. Neuropharmacology 42 (6), 837-845. doi:10.1016/s0028-3908(02)00034-5

Erbaş, O., Oltulu, F., and Taşkiran, D. (2012). Amelioration of Rotenone-Induced Dopaminergic Cell Death in the Striatum by Oxytocin Treatment. Peptides 38 (2), 312-317. doi:10.1016/j.peptides.2012.05.026

Everett, N. A., Baracz, S. J., and Cornish, J. L. (2020). The Effect of Chronic Oxytocin Treatment during Abstinence from Methamphetamine Self-Administration on Incubation of Craving, Reinstatement, and Anxiety. Neuropsychopharmacol. 45 (4), 597-605. doi:10.1038/s41386-019-0566-6

Everett, N. A., McGregor, I. S., Baracz, S. J., and Cornish, J. L. (2018). The Role of the Vasopressin V1a Receptor in Oxytocin Modulation of Methamphetamine Primed Reinstatement. Neuropharmacology 133, 1-11. doi:10.1016/ j.neuropharm.2017.12.036

Everett, N. A., Turner, A. J., Costa, P. A., Baracz, S. J., and Cornish, J. L. (2021). The Vagus Nerve Mediates the Suppressing Effects of Peripherally Administered Oxytocin on Methamphetamine Self-Administration and Seeking in Rats. Neuropsychopharmacol. 46 (2), 297-304. doi:10.1038/s41386-020-0719-7

Giancotti, F. G. (1997). Integrin Signaling: Specificity and Control of Cell Survival and Cell Cycle Progression. Curr. Opin. Cel. Biol. 9 (5), 691-700. doi:10.1016/s0955-0674(97)80123-8 
Insel, T. R., and Shapiro, L. E. (1992). Oxytocin Receptor Distribution Reflects Social Organization in Monogamous and Polygamous Voles. Proc. Natl. Acad. Sci. 89 (13), 5981-5985. doi:10.1073/pnas.89.13.5981

Kaneko, Y., Pappas, C., Tajiri, N., and Borlongan, C. V. (2016). Oxytocin Modulates Gabaar Subunits to Confer Neuroprotection in Stroke In Vitro. Scientific Rep. 6, 35659. doi:10.1038/srep35659

Karmarkar, S. W., Bottum, K. M., Krager, S. L., and Tischkau, S. A. (2011). ERK/ MAPK Is Essential for Endogenous Neuroprotection in scn2.2 Cells. Plos One 6 (8), e23493. doi:10.1371/journal.pone.0023493

Kish, S. J., Boileau, I., Callaghan, R. C., and Tong, J. (2017). Brain Dopamine Neurone 'damage': Methamphetamine Users vs. Parkinson's Disease - a Critical Assessment of the Evidence. Eur. J. Neurosci. 45 (1), 58-66. doi:10.1111/ejn.13363

Kremarik, P., Freund-Mercier, M. J., and Stoeckel, M. E. (2010). Autoradiographic Detection of Oxytocin- and Vasopressin-Binding Sites in Various Subnuclei of the Bed Nucleus of the Stria Terminalis in the Rat. Effects of Functional and Experimental Sexual Steroid Variations. J. Neuroendocrinol. 3 (6), 689-698. doi:10.1111/j.1365-2826.1991.tb00335.x

Lee, J. E., Park, J. H., Shin, I. C., and Koh, H. C. (2012). Reactive Oxygen Species Regulated Mitochondria-Mediated Apoptosis in Pc12 Cells Exposed to Chlorpyrifos. Toxicol. Appl. Pharmacol. 263 (2), 148-162. doi:10.1016/j.taap.2012.06.005

Lemasters, J. J., Qian, T., Bradham, C. A., Brenner, D. A., Cascio, W. E., Trost, L. C., et al. (1999). Mitochondrial Dysfunction in the Pathogenesis of Necrotic and Apoptotic Cell Death. J. Bioenerg. Biomembranes 31 (4), 305-319. doi:10.1023/a:1005419617371

Li, N., Ragheb, K., Lawler, G., Sturgis, J., Rajwa, B., Melendez, J. A., et al. (2003). Mitochondrial Complex I Inhibitor Rotenone Induces Apoptosis through Enhancing Mitochondrial Reactive Oxygen Species Production. J. Biol. Chem. 278 (10), 8516-8525. doi:10.1074/jbc.m210432200

Meller, R., Minami, M., Cameron, J. A., Impey, S., Chen, D., Lan, J.-Q., et al. (2005). Creb-mediated Bcl-2 Protein Expression after Ischemic Preconditioning. J. Cereb. Blood Flow Metab. 25 (2), 234-246. doi:10.1038/sj.jcbfm.9600024

Murphy, A. N., Fiskum, G., and Beal, M. F. (1999). Mitochondria in Neurodegeneration: Bioenergetic Function in Cell Life and Death. J. Cereb. Blood Flow Metab. 19 (3), 231-245. doi:10.1097/00004647-199903000-00001

Newhouse, K., Hsuan, S. L., Chang, S. H., Cai, B., Wang, Y., and Xia, Z. (2004). Rotenone-induced Apoptosis Is Mediated by P38 and Jnk Map Kinases in Human Dopaminergic Sh-Sy5y Cells. Toxicol. Sci. 79 (1), 137-146. doi:10.1093/toxsci/kfh089

Qi, J., Yang, J.-Y., Wang, F., Zhao, Y.-N., Song, M., and Wu, C.-F. (2009). Effects of Oxytocin on Methamphetamine-Induced Conditioned Place Preference and the Possible Role of Glutamatergic Neurotransmission in the Medial Prefrontal Cortex of Mice in Reinstatement. Neuropharmacology 56 (5), 856-865. doi:10.1016/j.neuropharm.2009.01.010

Qiao, D., Xu, J., Le, C., Huang, E., Liu, C., Qiu, P., et al. (2014). Insulin-like Growth Factor Binding Protein 5 (IGFBP5) Mediates Methamphetamine-Induced Dopaminergic Neuron Apoptosis. Toxicol. Lett. 230 (3), 444-453. doi:10.1016/j.toxlet.2014.08.010

Ramkissoon, A., and Wells, P. G. (2015). Methamphetamine Oxidative Stress, Neurotoxicity, and Functional Deficits Are Modulated by Nuclear Factor-E2-Related Factor 2. Free Radic. Biol. Med. 89, 358-368. doi:10.1016/j.freeradbiomed.2015.07.157

Sánchez-Vidaña, D. I., Chan, N. M., Chan, A. H., Hui, K. K., Lee, S., Chan, H. Y., et al. (2016). Repeated Treatment with Oxytocin Promotes Hippocampal Cell Proliferation, Dendritic Maturation and Affects Socio-Emotional Behavior. Neuroscience 333, 65-77. doi:10.1016/j.neuroscience.2016.07.005

Shah, A., and Kumar, A. (2016). Methamphetamine-mediated Endoplasmic Reticulum (ER) Stress Induces Type-1 Programmed Cell Death in Astrocytes via ATF6, IRE1 $\alpha$ and PERK Pathways. Oncotarget 7 (29), 46100-46119. doi:10.18632/oncotarget.10025

Smith, A. S., Ågmo, A., Birnie, A. K., and French, J. A. (2010). Manipulation of the Oxytocin System Alters Social Behavior and Attraction in Pair-Bonding Primates, callithrix Penicillata. Horm. Behav. 57 (2), 255-262. doi:10.1016/ j.yhbeh.2009.12.004

Srisurapanont, M., Ali, R., Marsden, J., Sunga, A., Wada, K., and Monteiro, M. (2003). Psychotic Symptoms in Methamphetamine Psychotic In-Patients. Int. J. Neuropsychopharm. 6 (4), 347-352. doi:10.1017/s1461145703003675

Stauffer, C. S., Moschetto, J. M., McKernan, S., Meinzer, N., Chiang, C., Rapier, R., et al. (2020). Oxytocin-enhanced Group Therapy for Methamphetamine Use Disorder: Randomized Controlled Trial. J. substance abuse Treat. 116, 108059. doi:10.1016/j.jsat.2020.108059
Sun-Young, L., Seong-Hae, P., Chihye, C., Kim, J. J., Se-Young, C., and Han, J. S. (2015). Oxytocin Protects Hippocampal Memory and Plasticity from Uncontrollable Stress. Scientific Rep. 5 (1), 18540. doi:10.1038/srep18540

Taylor, R. C., Cullen, S. P., and Martin, S. J. (2008). Apoptosis: Controlled Demolition at the Cellular Level. Nat. Rev. Mol. Cel. Biol. 9 (3), 231-241. doi:10.1038/nrm2312

Tomizawa, K., Iga, N., Lu, Y.-F., Moriwaki, A., Matsushita, M., Li, S.-T., et al. (2003). Oxytocin Improves Long-Lasting Spatial Memory during Motherhood through Map Kinase cascade. Nat. Neurosci. 6 (4), 384-390. doi:10.1038/ nn1023

Tribollet, E., Dubois-Dauphin, M., Dreifuss, J. J., Barberis, C., and Jard, S. (2010). Oxytocin Receptors in the central Nervous System. Distribution, Development, and Species Differences. Ann. N. Y Acad. Sci. 652 (1), 29-38. doi:10.1111/ j.1749-6632.1992.tb34343.x

Ulivi, P., Arienti, C., Zoli, W., Scarsella, M., Carloni, S., Fabbri, F., et al. (2010). In Vitro and In Vivo Antitumor Efficacy of Docetaxel and Sorafenib Combination in Human Pancreatic Cancer Cells. Ccdt 10 (6), 600-610. doi:10.2174/156800910791859489

Wagner, G. C., Carelli, R. M., and Jarvis, M. F. (1985). Pretreatment with Ascorbic Acid Attenuates the Neurotoxic Effects of Methamphetamine in Rats. Res. Commun. Chem. Pathol. Pharmacol. 47 (2), 221-228. doi:10.1016/02732300(85) $90045-5$

Wang, S. F., Yen, J. C., Yin, P. H., Chi, C. W., and Lee, H. C. (2008). Involvement of Oxidative Stress-Activated JNK Signaling in the Methamphetamine-Induced Cell Death of Human SH-Sy5y Cells. Toxicology 246 (2-3), 234-241. doi:10.1016/j.tox.2008.01.020

Wu, C.-W., Ping, Y.-H., Yen, J.-C., Chang, C.-Y., Wang, S.-F., Yeh, C.-L., et al. (2007). Enhanced Oxidative Stress and Aberrant Mitochondrial Biogenesis in Human Neuroblastoma Sh-Sy5y Cells during Methamphetamine Induced Apoptosis. Toxicol. Appl. Pharmacol. 220 (3), 243-251. doi:10.1016/j.taap.2007.01.011

Wu, P.-H., Shen, Y.-C., Wang, Y.-H., Chi, C.-W., and Yen, J.-C. (2006). Baicalein Attenuates Methamphetamine-Induced Loss of Dopamine Transporter in Mouse Striatum. Toxicology 226 (2), 238-245. doi:10.1016/j.tox.2006.06.015

Xu, S.-y., Hu, Y.-f., Li, W.-p., Wu, Y.-m., Ji, Z., Wang, S.-n., et al. (2014). Intermittent Hypothermia Is Neuroprotective in an In Vitro Model of Ischemic Stroke. Int. J. Biol. Sci. 10 (8), 873-881. doi:10.7150/ijbs.8868

Young, L. J. (2015). Oxytocin, Social Cognition and Psychiatry. Neuropsychopharmacol. 40 (1), 243-244. doi:10.1038/npp.2014.186

Zanos, P., Wright, S. R., Georgiou, P., Yoo, J. H., Ledent, C., Hourani, S. M., et al. (2014). Chronic Methamphetamine Treatment Induces Oxytocin Receptor UpRegulation in the Amygdala and Hypothalamus via an Adenosine A2a Receptor-independent Mechanism. Pharmacol. Biochem. Behav. 119, 72-79. doi:10.1016/j.pbb.2013.05.009

Zhang, X. J., Li, T. Y., Liu, Y. X., Qu, J., Wei, X. P., and He, J. (2010). Primary Culture of Rat Hippocampal Neurons and Detection of the Neuronal Excitability. Nan Fang Yi Ke Da Xue Xue Bao 30 (9), 2080-2083.

Zhu, J., Zang, S., Chen, X., Jiang, L., Gu, A., Cheng, J., et al. (2018). Involvement of the Delayed Rectifier Outward Potassium Channel Kv2.1 in Methamphetamine-Induced Neuronal Apoptosis via the P38 MitogenActivated Protein Kinase Signaling Pathway. J. Appl. Toxicol. 38 (5), 696-704. doi:10.1002/jat.3576

Conflict of Interest: The authors declare that the research was conducted in the absence of any commercial or financial relationships that could be construed as a potential conflict of interest.

Publisher's Note: All claims expressed in this article are solely those of the authors and do not necessarily represent those of their affiliated organizations, or those of the publisher, the editors and the reviewers. Any product that may be evaluated in this article, or claim that may be made by its manufacturer, is not guaranteed or endorsed by the publisher.

Copyright $\odot 2021$ Li, Wang, Wang, Chen, Bai, Ban and Wu. This is an open-access article distributed under the terms of the Creative Commons Attribution License (CC $B Y$ ). The use, distribution or reproduction in other forums is permitted, provided the original author(s) and the copyright owner(s) are credited and that the original publication in this journal is cited, in accordance with accepted academic practice. No use, distribution or reproduction is permitted which does not comply with these terms. 